\title{
Rhetorical Preferences in Persian Writing
}

\author{
Mehrnoosh Eslami \\ Shiraz Khabar Media School, University of Applied Science and Technology, Shiraz, Iran \\ Mahmoud Shaker \\ Shiraz Khabar Media School, University of Applied Science and Technology, Shiraz, Iran \\ Fatemeh Rakhshandehroo \\ Shiraz Khabar Media School, University of Applied Science and Technology, Shiraz, Iran
}

\begin{abstract}
A widespread assumption in the contrastive rhetoric field is the linearity/circularity dichotomy which suggests that eastern countries writing are characterized by indirection. This study examines the rhetorical preferences of Persian writing. A total of 320 essays taken from forty sophomore students studying English translation were analyzed. They were supposed to write an essay for eight weeks in different genres. To determine Persian writing style models by Chesterman, (1998) and Monroy and Scheu (1997) are used. Texts are analyzed in order to fit into one of the categories Chesterman has classified. Results indicate that Persian students, alike English learners, prefer directness in text and paragraph organization. In other words, they try to discuss their thesis statement directly at the beginning of their writing in order to support it in the rest of the paragraphs. Moreover, an examination of students essay reveal that the rhetorical preference of Persian language is linearity, the style English writing follows.
\end{abstract}

Index Terms - contrastive rhetoric, linearity, circularity, Persian rhetoric

\section{INTRODUCTION}

Linear development refers to pattern of writing organized around main idea. In other words, all the parts of writing should be related to central idea directly and straightly from the beginning to the end. In Standard English writing, the assessment of students' writing may be mostly done based on the criteria of "linear development". Based on this method, students mostly receive comment such as "disorganized", "out of focus", "irrelevant", "incoherent", or "loose tie with main idea", regarding their writing. ("Rhetorical Preferences", n.d.)

Although this pattern of linearity is not the only pattern for writing, but it is the most commonly used style in English writing. Kaplan (1966) was the first to realize the different patterns of writing. Moreover, he stated that these patterns are culturally preferred styles and differ from one culture and language to another. Examples of languages which do not follow the pattern of linearity are Chinese, Korean, Japanese, Thai, Hindi, French, and German.

To the best knowledge of the authors, no specific study has been conducted on Persian language in order to find its rhetorical preferences. Although different studies have been done on contrastive rhetoric between English and Persian in different aspects, no specific study has focused on rhetorical preferences in Persian language. Therefore, this study aims at revealing Persian writing style in order to improve students' difficulties in writing an essay in English, since there may be differences in their rhetorical preferences in writing.

\section{REVIEW OF LITERATURE}

Contrastive rhetoric refers to those problems in which L2 students may encounter during their writing and the effort to find the reason through rhetorical strategies of the first language (Connor, 1996). In his study Cahyono (2001) stated that studies on contrastive studies divided into two types. The first consists of writers from two cultures writing in the same language. Mostly the studies have taken into consideration English as a second language and other languages as the first language. The other type however, consists of writers from the same culture writing in two different languages. It was believed that both types are important since they explore issues such as "the extent to which differences in rhetorical strategies are due to differences in cultural patterns of thought and expression, differences in the languages themselves, or differences in the proficiency levels of writers". (P.44)

Chesterman (1988) introduced some different patterns of writing namely profile of a text as Linear, Parallel, Spiral, Scatter, Digressive and Listing although as he stated they are endless in number. Different studies were done on different languages to determine their specific rhetorical preferences. However, no study explores the same issue on Persian language. In order to reach this end, Chesterman categories are explained to see what characteristics they have and how they are culture specific. Moreover, some examples from different languages are provided to exemplify each style.

However, before doing any contrastive studies the concept of linearity should be defined so a linear/non-linear characteristic of a text in a given language can be determined. Since Kaplan introduced rhetorical preferences for each 
language, therefore based on different cultures, writing style may differ. English as an international language, for instance follow the pattern of linearity. However, it should not be thought that these patterns are homogeneous in academic writing. In other words, not all English writing styles are linear. Braddock (1974) reported by Smith (2008) proved that not all expository writings in English are started with main ideas and only $13 \%$ of them begin with topic sentences. Therefore, teachers should not emphasize teaching students to start with a main idea in their writing. Kachru(1995) reported that several languages such as English, Hindi, Japanese, Korean have more than one rhetorical mode. But as stated by Kaplan (1987) mentioned, “... while all forms are possible, all forms do not occur with equal frequency or in parallel distribution". Hence, the most frequent rhetorical style of each language is provided below to set a framework for checking rhetorical preferences of Persian language.

\section{A. English Style}

English follows the pattern of linearity. Two main features are the basic elements of this style, namely, unity and avoidance of repetition. Whenever, one single main theme is maintained in an essay and also one main idea expressed in each paragraph, the writing style is linear since it has unity. However if two main ideas are provided in each paragraph, that writing has a non-linear writing style, like Hindi language, and may follow the features of digression and indirection, such as French and German languages. In contrast to nonlinear languages which are specified by repetition, linear language seldom uses repetition except for strengthening the tone of the writing to enhance persuasiveness ("Rhetorical Preferences", n.d.).

In Monroy and Scheu (1997, cited in Monroy, 2008) some guidelines are established for a straight linear rhetorical pattern.

1) Thematic Unit (TU). This category is called to be present, whenever there is only one thesis in an essay in a way that it binds all parts to a single main idea.

2) Thematic Progression (TP). This category is called to be present, whenever the writer provides a relationship between all thematic sentences in each paragraph with the main thesis.

3) Paragraph Unity (PU). This category is called to be present, whenever the writer provides a monothematic structure and not a polythematic one, in a way that all sentences develop the controlling idea through expanding and illustrating it.

4) Personal tone (PT). According to Hinds, 1987 cited in Monroy (2008), this category refers to consistent point of view; writers responsible vs. reader responsible languages.

5) Inter-paragraph cohesion (CO). This category is called to be present, whenever there are linkages between paragraphs in a co-referential, co-classification or co-extensive way.

6) Concreteness $(\mathrm{CON})$. This category is called to be present, whenever the tendency is toward using more concrete words rather than abstract words.

7) Sentence Simplicity (SS). This category is called to be present, whenever the writer makes use of more simple and coordinate sentences rather than complex or subordinate sentences.

Therefore we can say that a writing style follows the pattern of linearity if it has the above mentioned characteristics. (See Appendix A to see an essay from English showing linearity taken from ("Rhetorical Preferences", n.d.).

\section{B. Chinese, Korean and Japanese Styles}

In these languages, writers mix different patterns. In fact, they can tolerate complex rhetorical structures in an essay which is not linearly organized. Their writing consisted of four stages: "beginning", "development", "turn", and "end" or as they called it qi-cheng-zhuan-he. Their writing is not developed in a straight line proceeding from a statement of the central idea followed by elaboration. Instead, the main idea is mentioned indirectly by talking about issues which are not directly related to the central idea.

Like other second language learners, they tend to unconsciously transfer their first language writing habits into English. Due to their complex style, their writing is confusing to English readers. Therefore, in writing classes they have to be aware about rhetorical preferences of different languages in order to adopt their style while writhing in other languages. ("Rhetorical Preferences", n.d.). An essay from Korean writing, cited in Eggington (1987, pp.155-156) and a Japanese writing provided by Hinds (1990) are provided to see the differences between these languages and English. (See Appendices B and C).

\section{French, German and Hindi Styles}

Digression or change of topic is Characteristic of French, German and Hindi writings. In German writing, digression mainly occurs to provide background information, give analysis, or comments on side-track topics (Clyne, 1987). In his study, Kachru (1988) also provided three main features of Hindi writing which shows its digressive pattern. Digression can be strategically used for providing additional information, suggesting alternative viewpoints on an issue, or it may be used as a hedging device or used for the purpose of humor. An English translation from French, cited in Kaplan (1966) and a German extract by Clyne (1987) are provided to illustrate this pattern. (See Appendices D and E).

\section{Thai Style}


This language follows the feature of repetition or overlay pattern as mentioned by Hinds (1990). Repetition can be purposefully used to strengthen the argument by repeated emphasis on a particular idea. Alternatively, it can be used to maintain coherence in the essay by linking evidence and claims. Repetition mostly found in non-linear styles of writing. However, repetition seldom appears in the linear style of English writing except for strengthening the tone in persuasion.

An untitled essay is taken from Hinds to illustrate Thai style (See Appendix F), however, Bickner and Peyasantiwong cited in Chesterman(1998) argue that Thais rhetorical preferences is "listing" since this style is frequent in Thai folk literature. In Listing as one type of writing style, all of the predications which are co-ordinated are subordinated to a single predication, as in [P1] IF [P2] AND [P3] AND [P4] etc. (Chesterman, 1998). He provides a sample from advertisers in Guardian Weekly newspaper (March 26, 1995) to illustrate the listing style in writing which are mostly occur in legislative provisions in English. (See Appendix G), which shows the first paragraph has a marked listing profile, stating the conditions, and the same profile dominates again at the end of the text.

\section{E. Arabic Style}

Arabic language in contrast to other languages follows the pattern of parallelism at both sentential and discoursal levels. Chesterman (1998) stated that in the pattern of parallelism, the texts "proceeds in a series of balanced pairs of predications, for instance reflecting contrasts or different facets of a single theme”. (p.172). In his studies, Ostler (1987) provideed a Sample from Students Essay in Discourse Bloc Form to show parallelism structure of Arabic style. (See Appendix H)

No specific language is leaning toward two of Chesterman profiles models namely Spiral and scatter. However it should be mentioned that Kachru (1988) stated that rhetorical preferences of Hindi language leaning toward circularity or spiral rhetorical pattern in expository prose. Based on Chesterman, in Spiral style "the text circles into or away from its Point in different directions, and is characterized by a lack of sequential cohesion". He provided an example (See Appendix I) to show that in spiral style, the central idea comes first and then additional information is stated in sentences that "might have been placed in several other orders". However in the latter style, scatter, the ideas in the text are scattered without much cohesion. (See Appendix J)

Chesterman classified this writing as scatter since the actual main idea remains so ambivalent: "the British athlete was actually defeated, but the structure of the text tends to make his achievement into a victory. Information about what happened two years ago, and who won the other two medals, is scattered here and there in such a way as to foreground the British viewpoint, like the scatter of a comet's tail".

Investigating all these models and literatures, this study hence was conducted to address the following research questions.

1. Do Persian students exhibit indirectness by delaying their thesis statement in their composition?

2. What is the rhetorical preference of the Persian language?

\section{METHOD}

In order to discover the rhetorical preference of Persian language, 320 essays written by 40 sophomore undergraduate students of Shiraz khabar Media school, Shiraz, Iran who were studying in the field of English Translation were gathered. In other words, forty students were supposed to write an essay for eight weeks, each week one as one of their writing class prerequisites. All compositions were written at home rather than in the class so that students have more time to organize their writing. Topics were chosen by their instructor and the genre of each writings differed every week.

For finding the pattern of writing, it is decided if most of the essays follow one of the rules in styles mentioned above, that pattern is considered as Persian rhetorical preferences and if it fits linearity it has to be checked through Monroy and Scheu (1997) model. Therefore, each text is analyzed in terms of the placement of main idea or thesis statement and then how it was elaborated to reach the concluding remarks. To avoid subjectivity two independent coders participated to establish inter-code reliability. One was an M.A student in TEFL with experience in teaching English as a second language in Iran. The other was an M.A student who was an experienced English EFL writing teacher. Twenty of the essays from students were randomly selected and analyzed. With regard to rhetorical preferences of Persian writing, they agreed on $95 \%$ of the judgment; coding the employment of rhetorical preferences the inter-code reliability was about $91 \%$.

\section{RESULT}

The entire subjects in this study prefer the initial placement of the thesis statement in all of the eight essays each of them wrote. These findings show that the Persian language prefers directness and directly states the central idea. Therefore, among Chesterman writing patterns, Persian language cannot follow digression, since in this style, as stated by Clyne (1987), the writer leaves an argument in mid-air and starts a new one. Moreover, Persian language cannot follow the nonlinearity pattern of Korean, Chinese and Japanese as far as the main idea is mentioned indirectly by talking about issues which are not directly related to the central idea. In contrast, Persian language alike English writing states the writer's position in introduction in order to elaborate on it in the rest of the essay. In English rhetoric, as stated by Christensen (1963), the topic sentence is the sentence "whose assertion is supported or whose meaning is explicated 
or whose parts are detailed in a paragraph" (P.236). To clarify the point one of the essays written by Persian students is provided to show how the writer locates the thesis statement in his writing.

$\begin{array}{ll}\text { Introduction } & \text { Removing Final Exam } \\ \text { Having courses based on formal exams may have some advantages, but its } \\ \text { disadvantages are significantly more. First of all, one or two exams cannot evaluate } \\ \text { students' weaknesses and strengths. By studying well at the night before the exam you } \\ \text { can get a wonderful grade; however, you haven't participated in class or haven't done the } \\ \text { assignments that your teacher has given each session. In addition, there is the possibility } \\ \text { of becoming sick or happening of bad events which would lead to less preparation for the } \\ \text { exam and as a result getting an awful grade or even failing the exam. Besides, for some } \\ \text { students exams are potentially stressful and this stress decreases their performance or } \\ \text { even worse they can't manage these stress and lose their control. To sum up, holding } \\ \text { one or two formal exams can't be helpful because its demerits are more than its } \\ \text { merits. }\end{array}$

Thesis Statement (Writer's Position)

Support of Writer's Position

Restatement of Writer's Position

Regarding the body section of the above example, all the essays elaborate on the central idea in order to support writer's position. None of the writers follow the pattern of circularity or spiral style because in this style as mentioned before the text lack the sequential cohesion. Moreover, the text circles around the main point in different direction. However, Persian writing analyzed in this study did not indicate such a style. In contrast, alike English language every part directly related to the central idea in a straight line from the beginning to the end. In the previous example, the entire cohesive tie in the body paragraph support writer's position. In other words, the writer supports the main idea directly with the help of cohesive ties in order to support the main idea. In the conclusion part, the writer then restates the main idea to end an essay. Another example in different genres is provided to illustrate the point more clearly.

How safe is Iran in comparison to London and New York?
Introduction
Just listening to some rumors. In spite of all the attempts to make Iran and Iranian look as if
they're a vicious and uncivilized society, statistics show that the converse is true. Based on
Some researches, New York and even London, surprisingly, outnumber Tehran in
much kind of crimes. For instance, while the number of pickpocketing in Tehran is about
1000, it reaches 5200 when it gets to London and up to 8700 in New York; there's also
mugging, which occurs around 3400 times per month in London, almost four times more
than in Tehran, which is about 800, and the number of mugging in New York is 6250 .
Moreover, with the police being careful about people not carrying guns, and weapons being
prohibited in Iran, reported cases regarding shooting and bank robbery are fewer than in the
other two cities. For instance, there are 10 similar cases per month in Tehran, 250 cases in
London and 10 times more in New York (around 2400); however, the only thing that might
look a little frightening is the number of car accidents taking place in Tehran. All in all, if a
visitor chooses Tehran instead of London, he's actually chosen a safer place for his/ her

All the essays written by students follow the same pattern. As it is obvious, this style is alike the English style. Therefore we can say that a rhetorical preference of Persian language is linearity. As such the essays were all analyzed to see whether they fit the seven features stated by Monroy and Scheu (1997). As there is only one thesis statement in each single essay, we can say that the Persian language has the feature of Thematic Unit (TU). Moreover, in the body paragraphs the thematic sentences relate to the main idea, thus Thematic Progression (TP) is present as well. Furthermore, each paragraph is related to each other aiming to expand and illustrate the main idea. As a result, Paragraph Unity (PU) is present in Persian writing. Personal tone (PT) also exists because the writers talk about the thesis statement in a consistent point of view. The fifth feature of linearity, Inter-paragraph cohesion (CO) is present as well since there are linkages between paragraphs in a co-referential way. Concreteness (CON) and Sentence Simplicity (SS) are also present in Persian writing as far as the writers mostly use concrete words rather than abstract and at the same time they use more simple sentences rather than complex ones.

\section{DISCUSSION}

From the initiation of contrastive rhetoric, English discourse pattern is described as linear, direct, and logical and languages in east such as Chinese, Korean and Japanese are characterize as circular, indirect and non-linear (Yung, 1994; Harris, 1997). This linearity/circularity dichotomy in contrastive rhetoric field implies that the culture of the east and the west and their respective rhetorical traditions differ profoundly and fundamentally. Such a view mostly is detrimental as it is liable to essentialize and construct "static, homogeneous, and apolitical images of the rhetorical patterns". (Kubota \& Lehner, 2004, P: 9) of written Chinese and English and rules out the possibility of any rhetorical similarities across the two cultures. However, Persian language in the east, in contrast to other eastern countries, follows the pattern of linearity which exists in most western countries. It should be mentioned that, non-linearity of eastern countries as stated above do not mean that they are not linear at all. Cahil (2003) for instance reveals that indirect/spiral style of Chinese and Japanese writing named as (zhuan/ten)"turn" is not a move of circularity or digression but rather an expansion development of preceding idea. This feature can be found in linear languages such as English as well. 
The finding in this study has direct pedagogical implications for EFL teachers. As Persian rhetorical discourse is alike English language and does not differ significantly from that of English and at the same time Persian students prefer directness in text and paragraph organization, therefore both ESL and EFL teachers can easily explain rhetorical pattern of English in order to make this unconscious knowledge tacit and obvious for Persian learners to follow in their writing.

This study also suggests some areas worthy of further research. How students are taught to write at school and how they learn to structure a text still remains unknown. It is suggested that more enquiry be made into students' learning experiences in writing in their native language and their perception of the difficulties in composition in their native language. Finally, for the purpose of EFL/ESL writing instruction, it would be valuable to compare the teaching of composition in Persian and English in Iran.

\section{CONCLUSION}

In light of the results of the study and the discussion of the results, two conclusions can be drawn. First, Persian students stated thesis statements at the very beginning of their writing. Furthermore, alike English writing they are direct and straightforward in their texts and paragraph organization. Second, essays analyzed from students all reveal that Persian writing alike English writing follows the pattern of linearity. Therefore, the Persian language can be classified as a linear language in which all parts relate to each other straightly and directly. This style alike pattern of English writing avoids any kind of repetition and at the same time has unity.

\section{APPENDIXES}

\section{A. English Style}

Should cloning be encouraged?

Nowadays, a lot of advances have been made in cloning technology. After mastering the techniques of cloning animals, scientists are now looking forward to the cloning of human beings. But ever since the cloning of Dolly the sheep, many questions have been raised about the likely consequences of human cloning on society. In spite of the many potential benefits can bring, cloning is likely to violate the moral principles of human society and usher in many problems.

Some people believe that cloning is beneficial to mankind as cloning technology can be used in medical science. For example, cloned organs can be used for organ transplants to save many lives. There would never be any worry of natural rejection [,] if the transplanted organ came from the cloned body of the [donor] patient. But it is an outrageous idea to clone human beings like cattle for the sole purpose of harvesting organs from them. If this were to come true, there would then be a new class of cloned 'slaves'. It is something no sane person in the 21 st century could in good conscience tolerate. The days of slavery are long gone in history.

It has also been argued that cloning can help infertile couples to have children. But even if the technology were available, cloned children would create problems for human society. The existing social system based on blood relations would be upset. Father and son, and mother and daughter would also be each other's siblings. This is hardly something we can adjust to easily.

As we can see, even if cloning is potentially beneficial to mankind, it can equally pose great risks and problems we may not be ready to face. Before we have clear answers to these questions, scientists would be ill advised to press on with cloning.

Introduction

"Writer's Position

Support of Writer's

Position

Conclusion

Restatement of Writer's

Position

\section{B. Korean Style}

Ki

Sung

kyul
The Ministry of Home Affairs is planning to strengthen the period of training for public officials from 3 days to 6 days per year in order to solidify the spirituality of the public officials. The training is to be conducted at the Spiritual Cultural Institute which is rendered in English as the Institute for Korean Studies.

A new meaning of "national" is attached to the word "spiritual". Perhaps this comes from the term "spiritual culture".

A member of the Korean Alphabet Society complained that the architectural design of the Institute for the Korean Studies resembles a Buddhist Temple and thus is not Korean. This is not so because Buddhism, though imported from India, is a Korean religion. Likewise Christianity is a Korean religion.

Any attempt to label what is national and what is foreign fails. Perhaps too much emphasis on nationalism may do more harm than good.

Instead of inspiring nationalism we should be appealing to universal reason and proper moral conduct. The civil spirit must take precedence over the national spirit.

I am reminded of this when, changing trains at the subway, I witness the rush to occupy seats on route to the sports centre where the Olympic Games are to be held. How do we enhance the nation's prestige through a sports event? As a teacher, I am partly responsible for this situation. Spiritual poverty is best observed in a metropolitan area like Seoul. Why is our public transport system so multi-layered with standing buses at the bottom, then regular buses, and finally taxis which move constantly to catch more passengers?

Once you catch a taxi you have to listen to the loud radio controlled by the driver.

"Dear administrators please do not talk about spiritual things unless you are interested in implementing concrete ethical conduct."

\section{Beginning of} argument

"Loose"

Development of

argument

\section{Main point}

of argument

Concepts indirectly connected with the argument

Conclusion of main theme 


\section{Japanese Style}

Ki

sho

ten
It is said that it is written at the entrance to a store in a tourist area somewhere, "Fee for asking the way, one time, 100 yen." This is a story which appeared in the column "Koe" of this newspaper. It's a fact that the world has become a difficult place to live in, but I think it is the reason that the storekeeper gives us, "It's become so much of a pain that I've acted this way."

While the experience of asking is only one on a particular day from the perspective of the on who is asked, it might be 20 times, or it might be 50 times.

Among these, there are probably people who leave without saying thank you, and those who ask the road from the inside of their cars. In the midst of his being busy there are probably people who ask the way in a rude manner. He probably even feels like saying. 'Just leave me alone.'

It's not only talk of asking the way: recently the habit of asking questions easily is spreading: Looking it up in the dictionary. Searching for a number in a telephone book. Looking at a map. Don't we ask too often without doing those things we should do?

Since even I go around asking people questions too often, I can't say very much, but in an overpopulated country like Japan, especially when you are asking questions, isn't it necessary to understand that your question is one of a 1,000 or one of 10,000 ?

There may be cases where the one who is asked, facing 1,000 or 10,000 people, is forced to provide 1,000 or 10,000 times the service. It worries me that people might not have a strong sense of consideration. There are other examples of lack of consideration too. One person throws away a cigarette butt on the station platform. The one who throws this away may think that it is not very important, but if 1,000 or 10,000 people throw them away, the platform will be filled with cigarette butts.

On garbage collection day, when someone throws away something that is still good, it can easily mean that it will swell to 1,000 or 10,000 times that. Swelling expenses to cover the costs of cleaning up cigarette butts and trash may lead to increases in railway fares and taxes.
Beginning: Introduction of theme

\section{Development:} Expansion of Introduction

Turn:

Additional or

background information related to main theme

The first point to which I would like to call your attention is that nothing exists outside the boundary of what is strictly human. A landscape may be beautiful, graceful, sublime, insignificant, or ugly; it will never be ludicrous. We may laugh at an animal, but only because we have detected in it some human expression or attitude. We may laugh at a hat, but we are not laughing at the piece of felt or straw. We are laughing at the shape that men have given to it, the human whim whose mold it has assumed.

I wonder why a fact so important has not attracted the attention of philosophers to a greater degree. Some have defined man as an animal that knows how to laugh. They could equally well have defined him as an animal which provokes laughter; for if any other animal or some lifeless object, achieves the same effect, it is always because of some similarity to man. 


\section{E. German Style}

The Carlist War

To attempt to understand the Carlism of the 19th century which was nominally a doctrine concerning the rightful Discontinuity: heir to the Spanish throne, it is essential to understand the Liberalism that was so popular in certain political and social circles at the time; and what this Spanish Liberalism signified to the prosperous, rural Basques. Furthermore, the fanatical Carlism of Navarra which was centered around the religious reunification of Spain must be distinguished from the more pragmatic Carlism of Vizcaya and Guipuzcoa which revolved around the preservation of the fueros. Before we start, however, it might be useful to examine very briefly two topics; the rural conditions of the Basques, and the differences between the four Spanish Basque provinces.

As Gerald Brenan has put it, rainfall is a critical factor in Spain, and in the Basque provinces rainfall is ample. An even distribution of resources combined with regular rainfall produced in the Basque provinces a large and prosperous yeoman class. Agrarian reformers attributed the prosperity of the Basque countryside to the caserio, the rural, the self-sufficient farmstead, which is the most prominent feature of the Basque rural landscape. The caserio, the concrete symbol of the Basque family, was founded on the small landholding which consisted of about ten to fifteen hectares. The caserio was an autonomous and self-supporting unit. Social and economic links between caserios were weak. Augmenting this system of small farms were communal forest and grazing lands which played an indispensable role in maintaining the general affluence of the Basques. In the Basque region a person's first loyalty was always directed toward the farmstead rather than toward a village which in the Spanish sense hardly existed.

But this view of the typical Basque countryside based on the caserio was by and large confined to Guipuzcoa an Vizcaya. In Alava and parts of Navarra the land is dryer, villages tend to replace farmhouses as the focal points, the presence of a landed gentry as evidenced by castles and fortresses is a more marked feature, and the Spanish crops of vines and wheat become more prominent. Some differences between the four provinces can be traced to geographical factors. Vizcaya and Guipuzcoa have been isolated from the rest of Spain by the Cantabrian mountain range; and historically have been more oriented toward the sea and the rest of Europe. Navarra, on the other hand, is cut off from France by the Pyrenees on one side, is separated from Guipuzcoa and Vizcaya by the Cantabrian, and merges with Aragon to the south. Alava, landlocked like Navarra, blends gradually into Old Castile, and has the climate and appearance of the Castilian meseta. Of further note is the fact that both Navarra and Alava have remained, unlike the two other Basque provinces, almost completely rural and isolated from industrial centers until the last ten to fifteen years.

Having said this much we can now turn our attention to the opposed ideologies of Liberalism and Carlism..

Discussion of main theme is left unfinished

\section{F. Thai Style}

\section{Marked Digression:}

signaled by preview in the end of previous paragraph;

for providing background information and analysis 
Although every advertisement is carefully checked, occasionally mistakes do occur. We therefore ask advertisers to assist us by checking their advertisements carefully and advise us immediately should an error occur. We regret that we cannot accept responsibility for more than ONE INCORRECT insertion and that no republication will be granted in the case of typographical or minor changes which do not affect the value of the advertisement.

H. Arabic Style

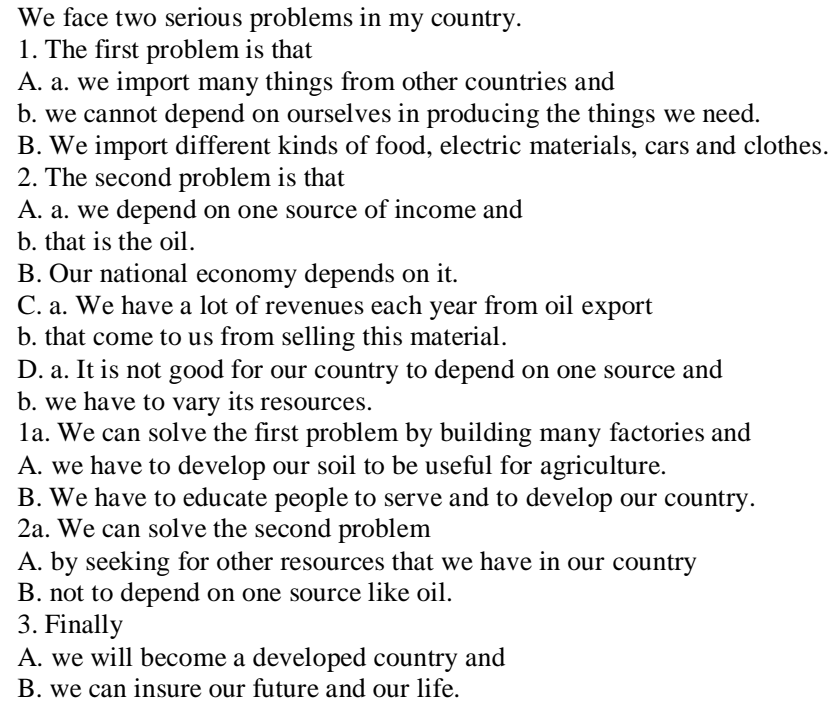

\section{Spiral Pattern}

Chris Eubank's 10-year unbeaten run came to an end in the Green Glens area at Millstreet, Co Cork, when Dublin's proudest fighting son, Steve Collins, beat him on a unanimous points decision to claim the WBO supermiddleweight crown. Eubank was knocked down in the eighth round and he then floored Collins in the tenth, but the Irishman was undisturbed. It was Eubank's first defeat in 44 bouts, 20 of which were WBO title fights. Collins said later: "I had no doubt I'd win. I'm the best pound-for-pound fighter in the world and no one can prove me wrong."

\section{J. Scatter Pattern}

Britain's Richard Nerurkar, winner of the 1993 World Marathon Cup, was pipped at the post in the Dong-A International Marathon in Seoul when he recorded a time of $2 \mathrm{hr} 11 \mathrm{~min} 3 \mathrm{sec}$ - five seconds behind the winner, Lee Bong-ju of South Korea. Mexican Andres Espinosa was third.

\section{ACKNOWLEDGMENTS}

The authors wish to sahow their gratitude to Dr. Naser Rashidi for his comments on an earlier version of the manuscript, although any errors are their own and should not tarnish the reputations of this esteemed person.

\section{REFERENCES}

[1] Cahil, D. (2003). The myth of the "turn" in contrastive rhetoric. Written communication, 20. 2, 170- 194.

[2] Cahyono, B. Y. (2001). Research studies in second language writing and in contrastive rhetoric, Jurusan Sastra Inggris, 3.1, $39-52$.

[3] Chesterman, A. (1998). Contrastive functional analysis. Amesterdam, Philadelphia: John Benjamin Publishing Company.

[4] Clyne, M. 1987. Cultural differences in the organization of academic texts: English and German. Journal of pragmatics, 11. 2, 211-241.

[5] Connor, U. (1996). Contrastive rhetoric: Cross Cultural Aspects of Second Language Writing, Cambridge: Cambridge University Press.

[6] Eggington, W. G. (1987). Written academic discourse in Korean: Implications for effective communication. In Conor and Kaplan. (eds). Writing across Languages: Analysis of L2 Text. Reading, MA: Addison-Wesley, 153-168.

[7] Harris, W. V. (1996). Reflections on the particular status of the personal. College English, 58. 8, 934-953.

[8] Hinds, J. (1990). Inductive, deductive, quasi inductive: Expository writing in Japanese, Korean, Chinese and Tai. In U. Connor and A.M. Johns (Eds.), Coherence in writing: research and pedagogical perspective, Alexandria, VA: TESOL, 87-110,.

[9] Kachru.Y.(1988). Writing in Hindi and English. In A. C. Purves (Eds.), Writing across languages and cultures. Newbury Park: Sage Publications, 109-137.

[10] Kachru,Y(1995). Cultural meaning and rhetorical styles: toward a framework for contrastive rhetoric. In Guy Cook and Barbara Seidlhofer (Eds.). Principle \& Practice in Applied Linguistics Oxford, England: Oxford University Press, 171-184.

[11] Kaplan, R. (1966). Cultural thought patterns in inter-cultural education. Language Learning, 16, 1-20. 
[12] Kaplan, R.B. (1987). Cultural thought patterns revisited. In U. Connor \& R. B. Kaplan (Eds.), Writing across languages: Analysis of L2 text. Reading, MA: Addison-Wesley, pp. 9-23.

[13] Kubota, R. \& Lehner,A. (2004). Toward critical contrastive rhetoric. Journal of second language Writing, 13, 7-27.

[14] Monroy, R. (2008). Liniearity in language: Rhetorical discursive Preferences in English and Spanish in the Light of Kaplan's Model. International journal of English studies, 8. 2, 173-189.

[15] Monroy, R. \& Scheu, D. (1997). Reflejo cultural en los estilos de hispanohablantes estudiantes de inglés como LE. Consideraciones pedagógicas. In Juan Conesa (Eds). Estudios de Lingüística Aplicada y Literatura. Homenaje Póstumo al Prof. Departamento de Filología Inglesa.Universidad de Murcia, 201-221.

[16] Ostler, S. E. (1987). English in parallels: a comparison of English and Arabic prose. In Connor and Kaplan (Eds.) Writing across languages: Analysis of L2 text. Reading, Mass: Addison-Wesley Publishing Company, pp. 169-185.

[17] Rhetorical Preferences. (n.d.). Retrieved June 11, 2016 from Lingnon university website, https://www.ln.edu.hk/eng/rhetoric/Rhetorical_Preferences.html.

[18] Smith, C. G. (2008). Braddock Revisited: The Frequency And Placement Of Topic Sentences In Academic Writing. The Reading Matrix, 8.1, 78 - 95.

[19] Young, L.W.L. (1994). Crosstalk and culture in Sino-American communication. Cambridge: Cambridge University Press.

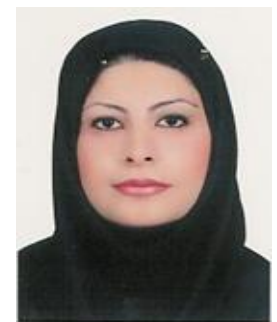

Mehrnoosh Eslami was born in Shiraz, Iran on September 20, 1987. She has been graduated from Shiraz State University in the field of Teaching English as a Foreign Language (TEFL) and received her M.A degree in 2012.

She was an INSTRUCTOR at Apadana Institute of Higher Education from 2011 till 2016 and also a teacher in an international school (Under IB Program) for 5 years. Furthermore, she was an ADMINISTRATIVE MANAGER in bilingual school since 2015. She is currently TEACHING ENGLISH COURSES to students of English Translation at University of Applied Science and Technology, Shiraz khabar Media school (2014now). At the same time, in the same university, she has been recently employed as DEPUTY OF RESEARCH, TECHNOLOGY AND ENTREPRENEURSHIP. She is also a LANGUAGE TECHNICAL EDITORof Iranian Journal of Material Forming (IJMF) from 2014 till now. She has published some articles and is interested in doing research on discourse analysis, teaching methodology, Bilingual and immersion programs, creativity in language classrooms and alike.

Mrs. Eslami is first rank holder of Sheikhbahaee and Shiraz State University for B.A and M.A degree in the field of English Literature and Teaching English as a Foreign language (TEFL) respectively. She has also gotten award for being an outstanding instructor at University of Applied Science and Technology, Shiraz KhabarMediaSchool.

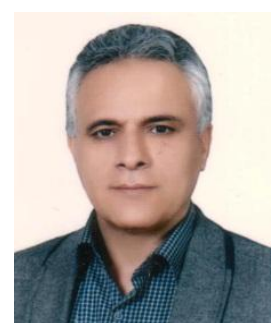

Mahmoud Shaker was born in Darab, Iran on November 18, 1966. He has been graduated from Shiraz state university in the field of English Literature and finished his M.A degree in the field of Physical Education and Sport Sciences from ShahidBeheshti University. Having interest in the field of future studies, he got his PhD. Degree from Isfahan University of Applied Science. He also got another M.A degree in the field if TEFL from Payam Noor University.

He was a Referee for many photo festivals and news articles and was the Head of Physical Education in Tehran, Pardis. He has been teaching in different universities such as Tehran University, ShahidBeheshti University, Azad University of Tehran, Shahriar Azad University, Tehran Khabar Media School, Shiraz Media school, Farhangian University and university of applied science and technology. Currently he is dean of Shiraz Khabar Media School, university of applied science and technology.He has presented articles in different conferences and published some articles and is interested in doing research on discourse analysis, teaching methodology, creativity in language classrooms, metacognition and alike.

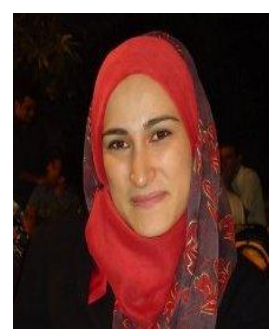

Fatemeh N. Rakhshandehroo was born in Shiraz, Iran on the 2nd of February, 1984. She moved to the United States with her family at the age of five and completed 6th grade at MacDonald Middle School, East Lansing, Michigan before moving back to Iran. Having completed high school in Iran, she earned her Bachelor of Arts in English translation from Shiraz Azad University in 2006. She moved back to the States for an M.A in TESOL in 2007. After taking some courses at California State University at Los Angeles and San Jose State University, she was forced to move back to Iran and transferred her degree to Shiraz University and completed her M.A in that institution.

Regarding her work experience, it must be noted that she has been an EFL teacher for nearly 15 years at different English institutes in the city of Shiraz, Iran. She has had experience working with young children as well as adults at most of the famous English Institutes in Shiraz, Iran. She also has experience working as a homeschooling tutor in San Jose, California. In recent years, she has taught English to 7th, 8th, and 9th graders at Mehr-e Taban Bilingual School. She is currently an EFL teacher who mainly teaches TOEFL and IELTS courses to adults and also conducts English speaking courses. 